\title{
Refined Zigzag Theory: an appropriate tool for the analysis of CLT-plates and other shear-elastic timber structures
}

\author{
Heinz Wimmer ${ }^{1,2} \cdot$ Werner Hochhauser ${ }^{2} \cdot$ Karin Nachbagauer $^{2} \oplus$
}

Received: 14 November 2019 / Published online: 28 August 2020

(c) The Author(s) 2020

\begin{abstract}
Cross laminated timber (CLT), as a structural plate-like timber product, has been established as a load bearing product for walls, floor and roof elements. In a bending situation due to the transverse shear flexibility of the crossing layers, the warping of the cross section follows a zigzag pattern which should be considered in the calculation model. The Refined Zigzag Theory (RZT) can fulfill this requirement in a very simple and efficient way. The RZT, founded in 2007 by A. Tessler (NASA Langley Research Center), M. Di Sciuva and M. Gherlone (Politecnico Torino) is a very robust and accurate analysis tool, which can handle the typical zigag warping of the cross section by introducing only one additional kinematic degree of freedom in case of plane beams and two more in case of biaxial bending of plates. Thus, the RZT-kinematics is able to reflect the specific and local stress behaviour near concentrated loads in combination with a warping constraint, while most other theories do not. A comparison is made with different methods of calculation, as the modified Gamma-method, the Shear Analogy method (SA) and the First Order Shear Deformation Theory (FSDT). For a test example of a two-span continuous beam, an error estimation concerning the maximum bending stress is presented depending on the slenderness $\mathrm{L} / \mathrm{h}$ and the width of contact area at the intermediate support. A stability investigation shows that FSDT provides sufficiently accurate results if the ratio of bending and shear stiffness is in a range as stated in the test example. It is shown that by a simple modification in the determination of the zigzag function, the scope can be extended to beams with arbitrary non-rectangular cross section. This generalization step considerably improves the possibilities for the application of RZT. Furthermore, beam structures with interlayer slip can easily be treated. So the RZT is very well suited to analyze all kinds, of shear-elastic structural element like CLT-plate, timber-concrete composite structure or doweled beam in an accurate and unified way.
\end{abstract}

Keywords Cross laminated timber $\cdot$ Refined Zigzag Theory $\cdot$ Shear-elastic timber structures $\cdot$ Interlayer slip

\section{Introduction}

Cross laminated timber (CLT), as a structural plate-like timber product, has been established as a load bearing product for walls, floor and roof elements and is in operation since about 30 years. Due to its high resistance, stiffness and adaptability to in-plane and out-of-plane load situations it is becoming increasingly popular among architects and

Karin Nachbagauer

karin.nachbagauer@fh-wels.at

Heinz Wimmer

h.wimmer@fh-kaernten.at

1 Carinthia University of Applied Sciences, Villacher Str. 1, 9800 Spittal, Austria

2 University of Applied Sciences Upper Austria, Stelzhamerstr. 23, 4600 Wels, Austria engineers. Despite of its important role and relevance in the timber construction sector it is not included in Eurocode 5, the European design standard for timber structures apart from National Application Documents. The current research activities are summarized in the state-of-the-art reports by Brandner et al. (2016, 2018). For the analysis of other types of shear-elastic composite members, several analytical and numerical methods can be found in the literature. According to its origin, the main focus of application of the RZT has so far mainly been to the engineering divisions of aviation and shipping as well as the automotive industry, where different composite materials have to be tailored to optimize the structural and thermal behaviour of such components.

When wooden parts are assembled into composite structural elements, their connections are usually characterized by a relatively high degree of deformability arising from shear strains. With CLT, this results from the orthotropic 
properties and the arrangement of the wooden boards. In other cases, this is due to the flexibility of discrete shear connectors. It is the explicit aim of this paper to show that RZT is a suitable and reliable means to analyze such structural elements in a uniform manner, which is demonstrated by examples given in Sect. 3 and 4.

\section{Design models for CLT-beams and -plates}

\subsection{Existing analysis methods}

In the following, mechanics of cross laminated timber plates under uniaxial bending caused by out-of-plane loads only is discussed. When dealing with CLT-plates, the transverse shear flexibility of the layers has to be considered. The large difference of the shear modulus of the neighbouring board layers leads to a non-planar warping of the cross section. To take into account this important fact, different kinematic models are developed. Well-known procedures are the Gamma-method (EN 1995-1-1 2015), originally used for composite beams with interlayer slip by Möhler (1956), which can be modified to apply to CLT and the Shear Analogy (SA) method introduced by Kreuzinger (1999) and worked out by Scholz $(2002,2004)$. For beams, the First Order Shear Deformation Theory (FSDT) by Reddy (2004), and Timoshenko's beam theory can be used when an appropriate shear correction factor is installed. The Gammamethod and the FSDT are not able to tackle the characteristic normal stress peaks that occur near intermediate support locations, nor the variability of shear stress pattern along such a beam. For the SA model, Scholz (2004) gave a series of analytical solutions for a single-span beam. For more complex beams, a numerical model with growing effort has to be established. As reported (Thiel 2013), the SA method overestimates the shear stress peaks close to point loads and inner supports, while the normal stress is quite accurate. In addition to the above mentioned simple beam models, there exist a large group of single layer (Abrate and Di Sciuva 2017) and layer-wise theories (Reddy 2004; Guggenberger and Moosbrugger 2006). The latter can be characterized as very accurate but very elaborate, because the number of kinematic variables is dependent on the number of layers.

\subsection{The Refined Zigzag Theory}

Among a further group of theories, named as Zigzag theories (Carrera 2003) the so-called Refined Zigzag Theory (RZT), developed by Tessler et al. (2009, 2010) and Tessler (2015) has proven to be one of the most promising approaches. This is due to its simple kinematics and superior capacity for the prediction of static, dynamic and buckling behaviour. The RZT takes the FSDT-kinematics as a base line and enhances it by a zigzag rotation $\psi(x)$, which controls a warping function $\phi(z)$ that can be estimated in advance from the sequence of layers and its material data. The kinematic relations for a beam in the $x-z$-plane are given in the fundamental paper (Tessler et al. 2009), where the axial displacements $u^{(k)}$ in $x$-direction and the transversal deflection $w^{(k)}$ in $z$-direction of the $k$-th layer were defined (Fig. 1).

$u^{(k)}(x, z)=u_{0}(x)+z \cdot \theta(x)+\phi^{(k)}(z) \cdot \psi(x)$

$w^{(k)}(x, z)=w(x)$

The zigzag function is defined in terms of its layer-interface values $\phi_{(i)}(i=0,1, \ldots, N)$. Using a local dimensionless coordinate $\zeta^{(k)} \in[-1,1]$, the linear function within each layer is defined by

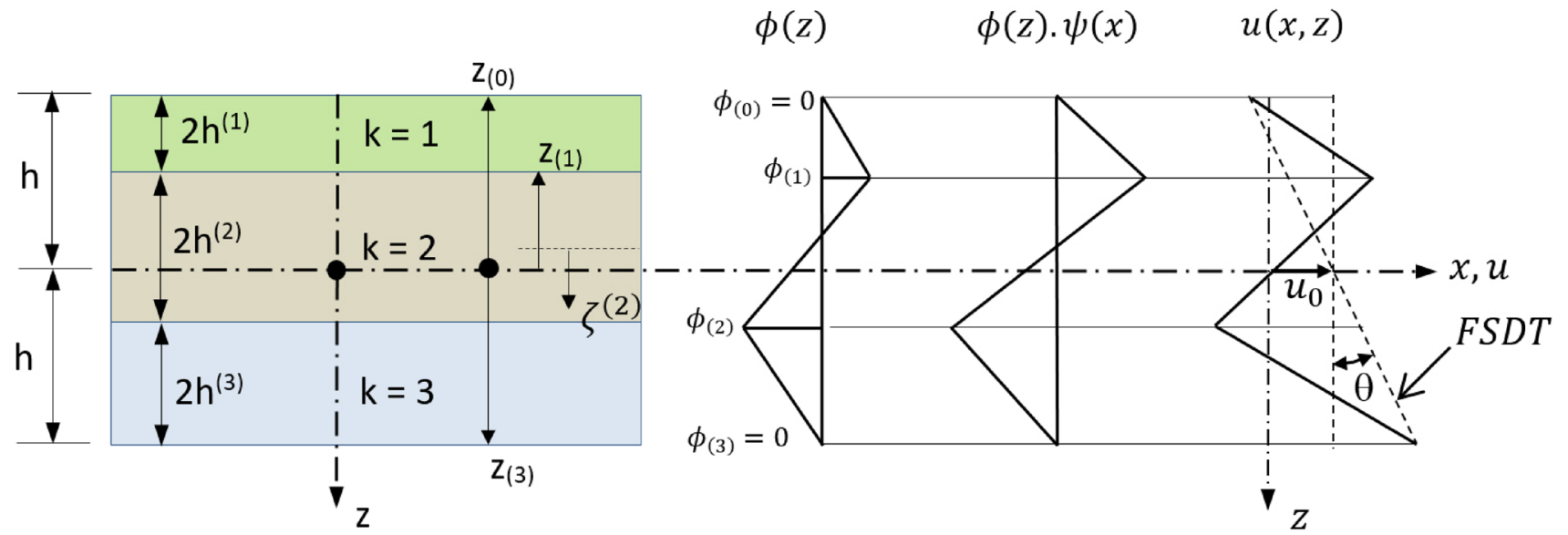

Fig. 1 Laminate of three layers with coordinate system and additive composition of axial displacements 
$\phi^{(k)}(z)=\frac{1}{2}\left(1-\zeta^{(k)}\right) \phi_{(k-1)}+\frac{1}{2}\left(1+\zeta^{(k)}\right) \phi_{(k)}$

Using the comma notation to denote partial differentiation, the corresponding strains from linear elasticity theory yield:

$$
\begin{aligned}
\varepsilon_{x}^{(k)}(x, z) & =\frac{\partial u^{(k)}}{\partial x}=u_{, x}^{(k)}=u_{0, x}+z \theta_{, x}+\phi^{(k)} \psi_{, x} \\
& =\left[1, z, \phi^{(k)}\right]\left\{\begin{array}{c}
u_{, x} \\
\theta_{, x} \\
\psi_{, x}
\end{array}\right\}=\mathbf{S}_{x} \cdot \tilde{\varepsilon}_{x}
\end{aligned}
$$

$$
\begin{aligned}
\gamma_{x z}^{(k)}(x, z) & =w_{, x}^{(k)}+u_{, z}^{(k)}=w_{, x}+\theta+\phi_{, z}^{(k)} \psi=\gamma+\beta^{(k)} \psi \\
& =\left[1, \beta^{(k)}\right]\left\{\begin{array}{c}
\gamma \\
\psi
\end{array}\right\}=\mathbf{S}_{x z} \cdot \tilde{\boldsymbol{\varepsilon}}_{x z}
\end{aligned}
$$

The function $\beta^{(k)}$ is the first derivative of the zigzag function $\phi^{(k)}$ after the variable $\mathrm{z}$ and is layer-wise constant (see Fig. 2). Thus, the shear strain and shear stress are layerwise constant. It represents the mean value and violates the demand of continuity of shear stresses beyond the layer interfaces. The key factor of RZT is the determination of the $\beta^{(k)}$-function in advance depending only on the stacking sequence and the transverse shear stiffness of each layer, represented by the shear modulus $G_{x z}^{(k)}$. In the fundamental paper by Tessler et al. (2009), the given procedure is related to rectangular cross sections, which means that all layers have the same width $b^{(k)}$, as shown in Fig. 2. Therefore, for a more general representation, the calculations are modified by considering a surrogate rectangular cross section (terms noted by a bar, see Fig. 3). With the widely used approximate formula of Jourawski (see Gere 2001) for the shear flow $t^{(k)}$ in each layer, the mean shear strains of the two cross sections are equated, and hence, the transformed $k$-th shear modulus $\bar{G}_{x z}^{(k)}$ is obtained (Fig. 3).

$\gamma_{m}^{(k)}=\frac{\tau^{(k)}}{G_{x z}^{(k)}}=\frac{t^{(k)}}{b^{(k)} G_{x z}^{(k)}}=\frac{t^{(k)}}{\bar{b}^{(k)} \bar{G}_{x z}^{(k)}} \rightarrow \bar{G}_{x z}^{(k)}=\frac{b^{(k)}}{\bar{b}} G_{x z}^{(k)}$

With these values, the calculation for the overall modulus $\bar{G}$ of the whole laminate and the modified terms for the $\beta^{(k)}$ -function are performed. For details see Tessler (2015).

$\bar{G}=\frac{\bar{A}}{\int \frac{d \bar{A}}{\bar{G}_{x z}^{(k)}}}=\frac{\bar{b} \sum h^{(k)}}{\int \frac{\bar{b}}{\left(b^{(k)} / \bar{b}\right) G_{x z}^{(k)}} d z}=\frac{\bar{b} \sum h^{(k)}}{\int \frac{(\bar{b})^{2}}{b^{(k)} G_{x z}^{(k)}} d z}$

Setting $\bar{b}=1$ we get

$\bar{G}=\frac{\sum h^{(k)}}{\sum\left(\frac{h^{(k)}}{b^{(k)} G_{x z}^{(k)}}\right)}$

And finally the modified $\beta^{(k)}$-function reads

$\bar{\beta}^{(k)}=\frac{\bar{G}}{b^{(k)} G_{x z}^{(k)}}-1$
Fig. 2 Zigzag function $\phi(z)$ and its first derivative $\beta(z)$ for a 5-layer CLT-plate consisting of two materials M1 and M2 (see example 1)

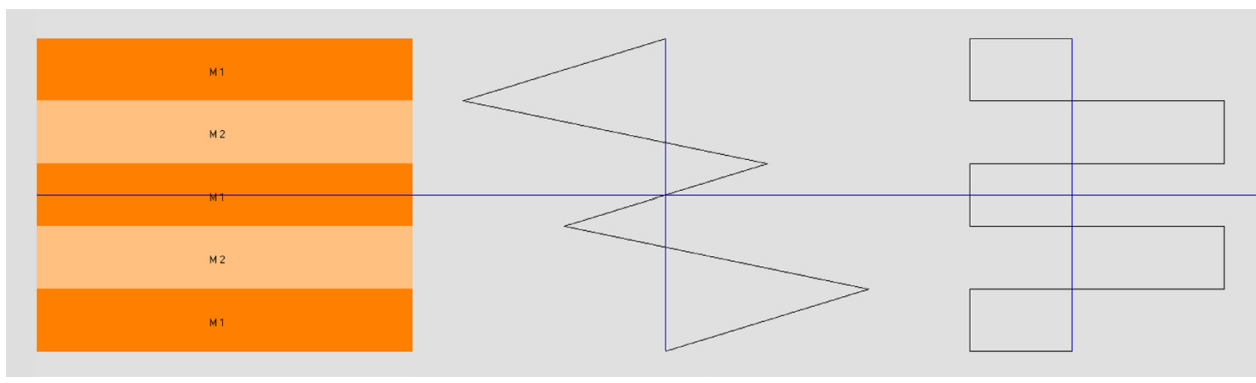

Fig. 3 Modification of $\beta^{(k)}$ -function in case of a symmetric non-rectangular laminate

$$
\begin{aligned}
& b^{(1)}, G_{x z}^{(1)} \\
& b^{(2)}, G_{x z}^{(2)} \\
& b^{(3)}, G_{x z}^{(3)} \\
& b^{(4)}, G_{x z}^{(4)}
\end{aligned}
$$

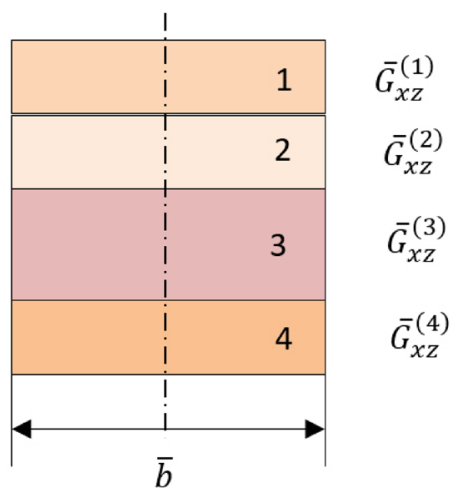


By integration over the layer thickness, the zigzag function $\phi(z)$ is established (see Figs. 1, 2). With $\phi_{(0)}=0$, the values at the interfaces are obtained by

$\phi_{(k)}=\phi_{(k-1)}+2 h^{(k)} \bar{\beta}^{(k)}, \quad k=1, \ldots, N$,

and the following equation is satisfied as in the original version

$\int \bar{\beta}^{(k)} d \bar{A}=0$

With the assumptions that each layer is linearly elastic and orthotropic corresponding to the Cartesian coordinates $(x, z)$, the constitutive relations take the form

$\sigma_{x}^{(k)}=E^{(k)} \varepsilon_{x}^{(k)}=E^{(k)} \mathbf{S}_{x} \tilde{\varepsilon}_{x}$

$$
\begin{aligned}
\tau_{x z}^{(k)} & =G_{x z}^{(k)} \gamma_{x z}^{(k)}=G_{x z}^{(k)} \gamma+G_{x z}^{(k)} \bar{\beta}^{(k)} \psi= \\
& =G_{x z}^{(k)} \mathbf{S}_{x z} \tilde{\varepsilon}_{x z}
\end{aligned}
$$

For a plate in plain strain in the width direction $E^{(k)}=E_{x x}^{(k)} /\left(1-v_{x y}^{(k)} \nu_{v x}^{(k)}\right)$, for a beam under plane stress conditions $E^{(k)}=E_{x x}^{(k)}$. $E_{x x}^{(k)}$ and $G_{x z}^{(k)}$ are the Young's modulus and shear modulus of the $k$-th layer, while $v_{x y}^{(k)}, v_{y x}^{(k)}$ denote the major and minor Poisson's ratios (Reddy 2004). The resultant stress vectors, $\tilde{\boldsymbol{\sigma}}_{x}$ and $\tilde{\boldsymbol{\sigma}}_{x z}$, and the generalized constitutive matrix are obtained with Eqs. (4) and (5) by integration over the cross section area (each layer has thickness $h^{(k)}$ and can exhibit a width $\left.b^{(k)}\right)$.

$$
\begin{aligned}
\tilde{\boldsymbol{\sigma}}_{x}^{\top} & =\left[N_{x}, M_{x}, M_{\phi}\right]=\int_{A}\left[\sigma_{x}^{(k)}, z \sigma_{x}^{(k)}, \phi^{(k)} \sigma_{x}^{(k)}\right] d A \\
& =\int_{A} \mathbf{S}_{x}^{\top} \sigma_{x}^{(k)} d A=\int_{A} \mathbf{S}_{x}^{\top} E_{x}^{(k)} \mathbf{S}_{x} \tilde{\varepsilon}_{x} d A \\
& =\int_{A} E^{(k)}\left[\begin{array}{ccc}
1 & z & \phi^{(k)} \\
z & z^{2} & z \phi^{(k)} \\
\phi^{(k)} & z \phi^{(k)} & \phi^{(k) 2}
\end{array}\right] d A \tilde{\varepsilon}_{x} \\
& =\left[\begin{array}{ccc}
A_{11} & B_{12} & B_{13} \\
B_{12} & D_{11} & D_{12} \\
B_{13} & D_{12} & D_{22}
\end{array}\right] \tilde{\varepsilon}_{x} \\
\tilde{\sigma}_{x z}^{\top} & =\left[\begin{array}{lll}
V_{x}, V_{\phi}
\end{array}\right]=\int_{A}\left[\tau_{x}^{(k)}, \bar{\beta}^{(k)} \tau_{x}^{(k)}\right] d A \\
& =\int_{A} \mathbf{S}_{x z}^{\top} \tau_{x z}^{(k)} d A=\int_{A} \mathbf{S}_{x z}^{\top} G_{x z}^{(k)} \mathbf{S}_{x z} \tilde{\varepsilon}_{x z} d A \\
& =\int_{A} G_{x z}^{(k)}\left[\begin{array}{cc}
1 & \bar{\beta}^{(k)} \\
\bar{\beta}^{(k)} & \bar{\beta}^{(k) 2}
\end{array}\right] d A \tilde{\varepsilon}_{x z} \\
& =\left[\begin{array}{ll}
Q_{11} & Q_{12} \\
Q_{12} & Q_{22}
\end{array}\right] \tilde{\varepsilon}_{x z}
\end{aligned}
$$

Combining Eqs. (14a), (14b) leads to

$$
\begin{aligned}
\tilde{\boldsymbol{\sigma}} & =\left\{\begin{array}{c}
\tilde{\boldsymbol{\sigma}}_{x} \\
\tilde{\boldsymbol{\sigma}}_{x z}
\end{array}\right\}=\left\{\begin{array}{c}
N_{x} \\
M_{x} \\
M_{\phi} \\
V_{x} \\
V_{\phi}
\end{array}\right\}=\left[\begin{array}{ccccc}
A_{11} & B_{12} & B_{13} & 0 & 0 \\
B_{12} & D_{11} & D_{12} & 0 & 0 \\
B_{13} & D_{12} & D_{22} & 0 & 0 \\
0 & 0 & 0 & Q_{11} & Q_{12} \\
0 & 0 & 0 & Q_{12} & Q_{22}
\end{array}\right]\left\{\begin{array}{c}
u_{, x} \\
\theta_{, x} \\
\psi_{, x} \\
\gamma \\
\psi
\end{array}\right\} \\
& =\mathbf{D}\left\{\begin{array}{c}
\tilde{\boldsymbol{\varepsilon}}_{x} \\
\tilde{\boldsymbol{\varepsilon}}_{x z}
\end{array}\right\}=\mathbf{D} \tilde{\boldsymbol{\varepsilon}}
\end{aligned}
$$

The variation of strain energy can be expressed in terms of generalized stresses and strains

$\delta U=\int_{L}\left(\delta \tilde{\boldsymbol{\varepsilon}}_{x}^{\top} \tilde{\boldsymbol{\sigma}}_{x}+\delta \tilde{\boldsymbol{\varepsilon}}_{x z}^{\top} \tilde{\boldsymbol{\sigma}}_{x z}\right) d x$

It contains derivatives of the kinematic quantities of first order only. Consequently, for a finite element model a $\mathrm{C}^{0}$ -approximation is sufficient. For further details, the reader is referred to Wimmer and Gherlone (2017). The classical RZT is verified by comparison with exact analytical solutions given by Pagano (1969) and high fidelity 2D-FE calculations. Such assessments are performed by Iurlaro et al. (2013, 2016). An extended version of RZT, called RZT ${ }^{(m)}$ is derived from Reissner's Mixed Variational Theorem by Tessler (2015). It leads to very accurate shear stress distributions that satisfy the equilibrium conditions along all layer interfaces and at the outer surfaces as well.

\subsection{Implementations of RZT-beams}

For a finite element approximation only $\mathrm{C}^{0}$ continuous kinematic approximations are required. A first element was developed by Gherlone et al. (2011), who have introduced an anisoparametric shape function for transverse deflection $w(x)$, which guarantees that no shear locking will occur. Oñate et al. (2012) presented an isoparametric element with selective reduced integration to prevent shear locking. Wimmer and Gherlone (2017) gave explicit expressions for the linear stiffness, the geometric stiffness, mass matrices as well as for the consistent load vector based on the anisoparametric approach. Nallim et al. (2017) presented a hierarchical p-type finite element, while Iurlaro et al. (2015) developed a beam element based on a higher order zigzag theory, where thickness stretching is also taken into account. Recently, applications of the mixed version of RZT are given by Groh and Tessler (2017) and Kefal et al. (2018). Wimmer and Nachbagauer (2019) treated beams on two-parameter elastic foundation. Additional aspects concerning the zigzag function are presented by Gherlone (2013) and Flores et al. (2018). A different numerical approach is presented by Wimmer and Nachbagauer (2018), where the governing first order differential equation system of the mechanical problem is formulated and solved by the transfer matrix method. For 
the static case, an exact expression of the transfer matrix is developed by similarity transformation, which provides analytically exact results for the kinematic variables and their first derivatives as well. This approach has the advantage that no error-prone smoothing process is involved to get the beam strains and stresses. Moreover, the transfer matrix allows for the derivation of a further finite beam element, which provides exact deformation results with coarse discretization. For the dynamic case, a series solution can be invoked to get the transfer matrix.

\section{Composite timber structures with interlayer slip}

The RZT is well suited for the analysis of composite beams, where special shear connectors (shear studs, nails etc.) are responsible for the interaction of the subcomponents. The behaviour of such members is quite complex and requires the consideration of the compliance of the connection, which leads to an interlayer slip between the different members. There are numerous proposals for the analysis of mostly twolayer composite members based on analytical or numerical models (Girhammar and Gopu 1993; Girhammar and Pan 1993, 2007; Adam et al. 1997; Salari and Spacone 2001; Faella et al. 2002; Ranzi et al. 2004; Ranzi and Bradford 2007; Xu and Wu 2007a, b; Schnabel et al. 2007; Schnabel and Planinc 2011; Nguyen et al. 2011; Nguyen and Hjiaj

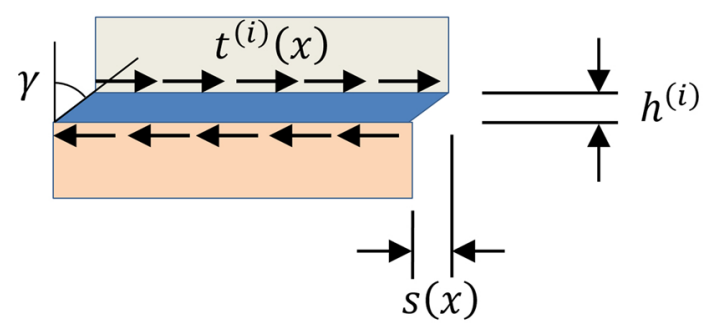

Fig. 4 Interlayer slip and shear gap
2012). Considering a shear flexible thin layer with thickness $h^{(i)}$ and a shear flow $t^{(i)}(x)$ acting on it, we get the shear slip $s(x)$, accepting a linear slip law, by

$s(x)=\frac{t^{(i)}(x)}{c_{s}}=\frac{\tau^{(i)}(x) \cdot b^{(i)}}{c_{s}}$

Herein $c_{s}$ denotes the shear stiffness and $b^{(i)}$ the width of interfacing layer. Otherwise, we get the shear slip by Hooke's law (Fig. 4)

$s(x) \cong \gamma^{(i)}(x) \cdot h^{(i)}=\frac{\tau^{(i)}(x)}{G_{x z}^{(i)}} \cdot h^{(i)}=\frac{t^{(i)}(x)}{b^{(i)} G_{x z}^{(i)}} \cdot h^{(i)}$

Equating (17) and (18) leads to the fictitious shear modulus $G_{x z}^{(i)}$ of the interfacing layer

$G_{x z}^{(i)}=\frac{c_{s} h^{(i)}}{b^{(i)}}$

With the help of the proposed model, it is also possible to simulate the effect of thin adhesive layers in any kind of sandwich and composite beam (Huang 2003).

\section{Examples}

As a first reference example, a double span beam "T2" with equal length of $\mathrm{L}=4.80 \mathrm{~m}$ is chosen (Bogensperger et al. 2012). The cross section consists of five layers with $32 \mathrm{~mm}$ thickness each, the width is fixed with $1000 \mathrm{~mm}$. Material data are as follows: Material M1: $E_{0}=11600 \mathrm{~N} / \mathrm{mm}^{2}, G_{0}=$ $720 \mathrm{~N} / \mathrm{mm}^{2}$, Material M2: $E_{90}=0 \mathrm{~N} / \mathrm{mm}^{2}, G_{90}=G_{R}=72$ $\mathrm{N} / \mathrm{mm}^{2}$. Layer-Sequence: M1-M2-M1-M2-M1. Distributed load $p_{z}=5 \mathrm{kN} / \mathrm{m}^{2}$. For details of the 2D-FEM models see Bogensperger et al. (2012). Table 1 shows the differences of various calculation methods. The result of RZT is obtained via 200 anisoparametric 2 -noded beam elements in each span. Further comparisons were made based on a more realistic support condition, whereas the reaction force is uniformly distributed over a length $\mathrm{a}=192 \mathrm{~mm}$. Figures 5, 6, 7 and 8 show the distribution of normal stress, mean shear
Table 1 Selected results with various calculation methods ${ }^{\text {a }}$ Bogensperger et al. (2012) and RZT, ${ }^{\mathrm{b}}$ max. mean value in layer

\begin{tabular}{lllllll}
\hline & $\begin{array}{l}\text { FSDT }^{\mathrm{a}} \\
{\left[\mathrm{N} / \mathrm{mm}^{2}, \mathrm{~mm}\right]}\end{array}$ & $\begin{array}{l}\text { Mod. } \gamma \text {-method }^{\mathrm{a}} \\
{\left[\mathrm{N} / \mathrm{mm}^{2}, \mathrm{~mm}\right]}\end{array}$ & $\begin{array}{l}\mathrm{SA}^{2} \text { method }^{\mathrm{a}} \\
{\left[\mathrm{N} / \mathrm{mm}^{2}, \mathrm{~mm}\right]}\end{array}$ & $\begin{array}{l}2 \mathrm{D}-\mathrm{FE} \_1^{\mathrm{a}} \\
{\left[\mathrm{N} / \mathrm{mm}^{2}, \mathrm{~mm}\right]}\end{array}$ & $\begin{array}{l}\text { 2D-FE_2 } \\
{\left[\mathrm{N} / \mathrm{mm}^{2}, \mathrm{~mm}\right]}\end{array}$ & $\begin{array}{l}\text { RZT } \\
{\left[\mathrm{N} / \mathrm{mm}^{2}, \mathrm{~mm}\right]}\end{array}$ \\
\hline$\sigma_{\max }$ & 4.167 & 4.224 & 5.955 & $\mathbf{6 . 4 3 2}$ & 4.832 & 5.51 \\
$\tau_{\max }$ & 0.120 & 0.120 & 0.228 & $\mathbf{0 . 1 7 6}$ & 0.138 & $0.146^{\mathrm{b}}$ \\
$w_{\max }$ & 5.51 & 5.50 & 5.47 & $\mathbf{5 . 4 8}$ & 5.48 & 5.46 \\
& $\%$ & $\%$ & $\%$ & $\%$ & $\%$ & $\%$ \\
$\sigma_{\max }$ & 64.8 & 65.7 & 92.6 & $\mathbf{1 0 0}$ & 75.1 & 85.7 \\
$\tau_{\max }$ & 68.2 & 68.2 & 128.4 & $\mathbf{1 0 0}$ & 78.4 & 83.0 \\
$w_{\max }$ & 100.5 & 100.4 & 99.8 & $\mathbf{1 0 0}$ & 100 & 99.6 \\
\hline
\end{tabular}


Fig. 5 Comparison of maximum bending stress $\sigma_{\max }(x)$ in the top layer along the beam
Fig. 6 Comparison of mean shear stress $\tau_{x z}(x)$ in the top layer (strong layer)

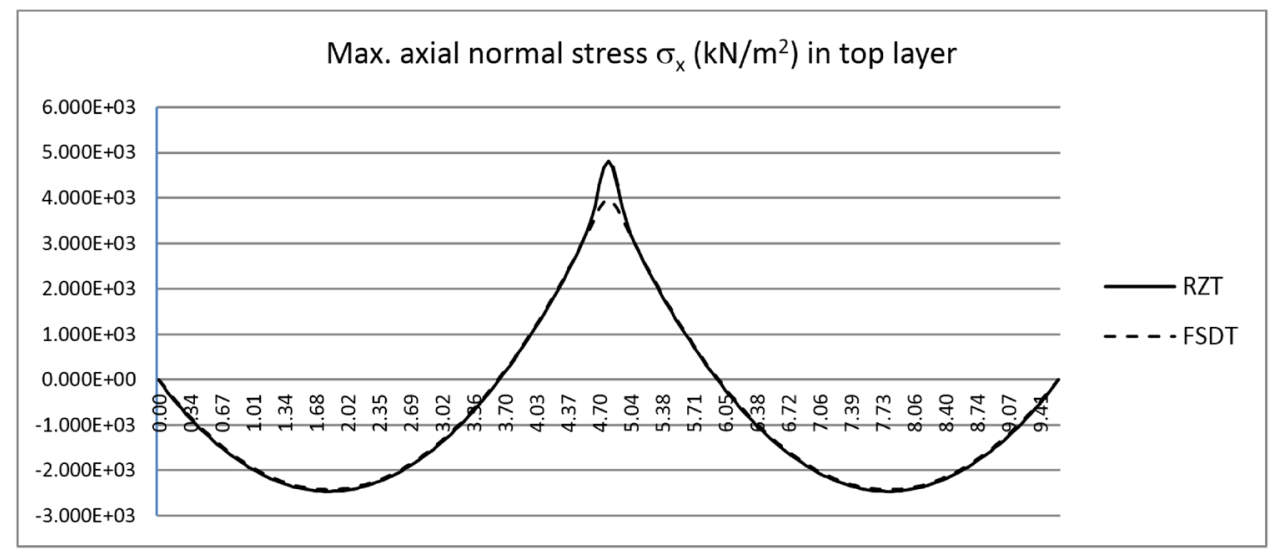

Fig. 7 Comparison of mean shear stress $\tau_{x z}(x)$ in the second layer (weak layer)

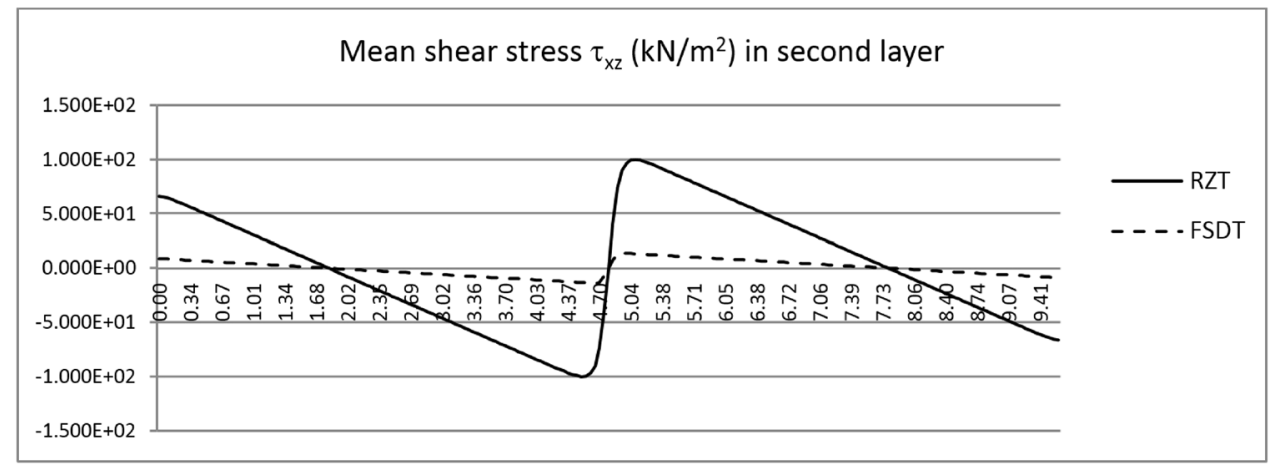

stresses and first derivative $\psi^{\prime}$ of the zigzag rotation. With the latter we are able to localize the specific sector, where the normal stresses deviate from the FSDT type.

Using the latter, the stress peak at the inner support is considerably underestimated. Figure 9 reports the deviation of FSDT-based results from the more accurate values of RZT concerning the maximum bending stress at the intermediate support for two cases of contact. The difference decreases with rising slenderness $\mathrm{L} / \mathrm{h}$ and contact width $a$ of the reaction force. A noticeable difference between the two approaches is shown in Fig. 7, where the FSDT considerably underestimates the mean shear stress in the weak layer (rolling shear). As a second example a stability investigation is made with a comparison between FSDT and RZT. The same beam as before was chosen but with a span $\mathrm{L}=3.00 \mathrm{~m}$. The initial external normal force is set to $F_{x}=100 \mathrm{kN}$ at the right end. In Table 2, the first three eigenvalues of buckling analysis are shown for pinned supports and for clamped support on the left end. In Fig. 10, the corresponding buckling modes are presented.

It should be noticed that the current approach is able to distinguish additional types of boundary conditions in an 
Fig. 8 Distribution of the first derivative $\psi^{\prime}(x)$ of the zigzag rotation which controls the bending stress
Fig. 9 Error of FSDT-based maximum normal stress at intermediate support relative to RZT-result
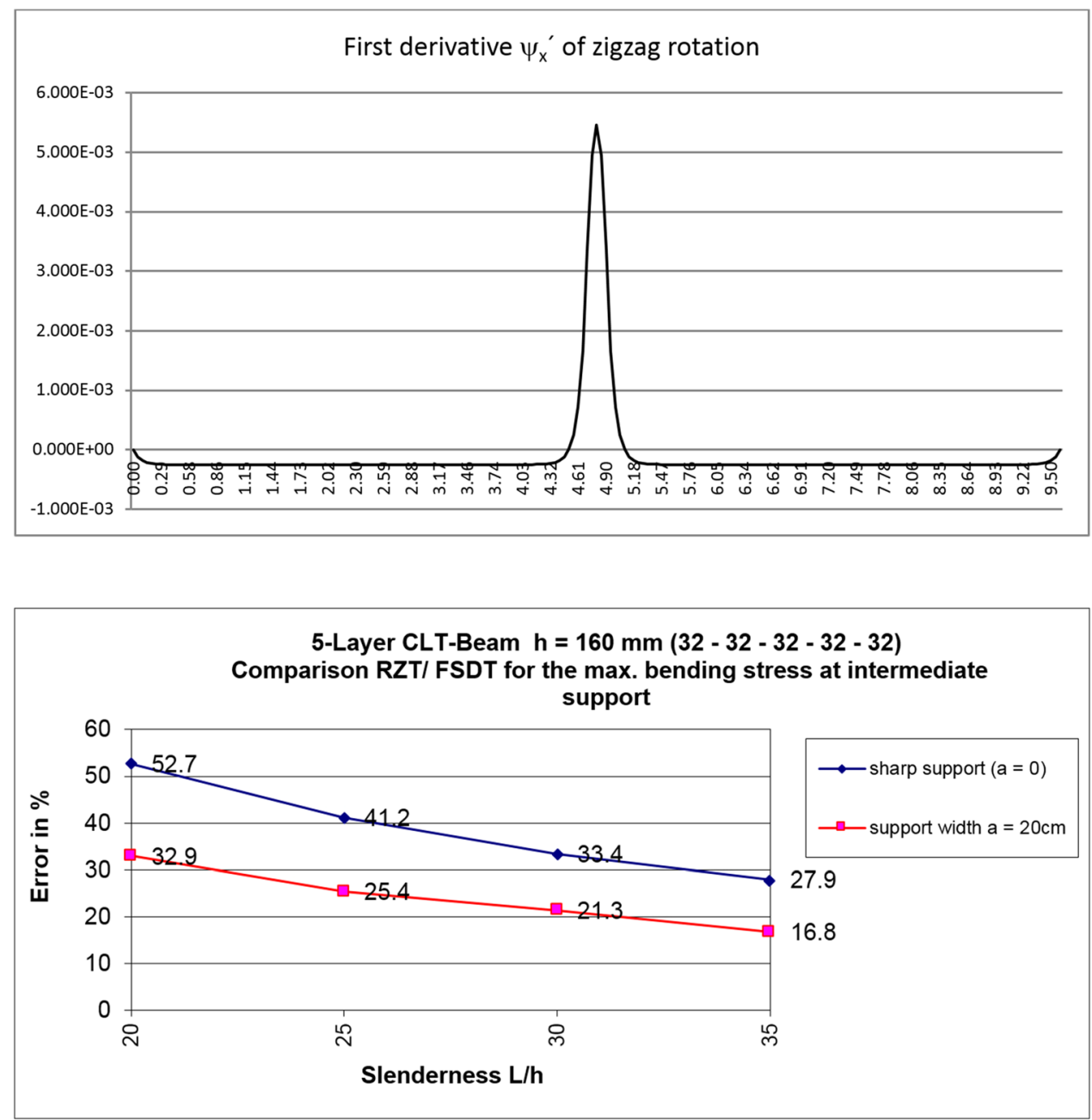

Table 2 Buckling eigenvalues concerning a constant initial normal force of $\mathrm{N}=-100 \mathrm{kN}$

\begin{tabular}{llllll}
\hline Mode & \multicolumn{2}{l}{ Pinned support } & & \multicolumn{2}{l}{$\begin{array}{l}\text { Clamped support (at } \\
\text { left end) }\end{array}$} \\
\cline { 2 - 3 } \cline { 5 - 6 } & FSDT & RZT & & FSDT & RZT \\
\hline 1 & 28.86 & 28.95 & & 34.80 & 35.00 \\
2 & 49.19 & 49.60 & & 65.03 & 65.72 \\
3 & 77.89 & 78.99 & & 87.39 & 89.00 \\
\hline
\end{tabular}

easy way. For the pinned as well as the clamped end the value of the zigzag rotation $\psi$ can be prescribed or not (see example in Wimmer and Gherlone 2017) whereby the warping of the beam's end cross section is controlled.

The third example, related to a non-rectangular cross section, is the widely referenced composite beam of Girhammar and Gopu (1993) and Girhammar and Pan (1993). This member is analyzed by introducing a fictitious interface layer of $1 \mathrm{~mm}$ thickness (Fig. 11). Following Eq.

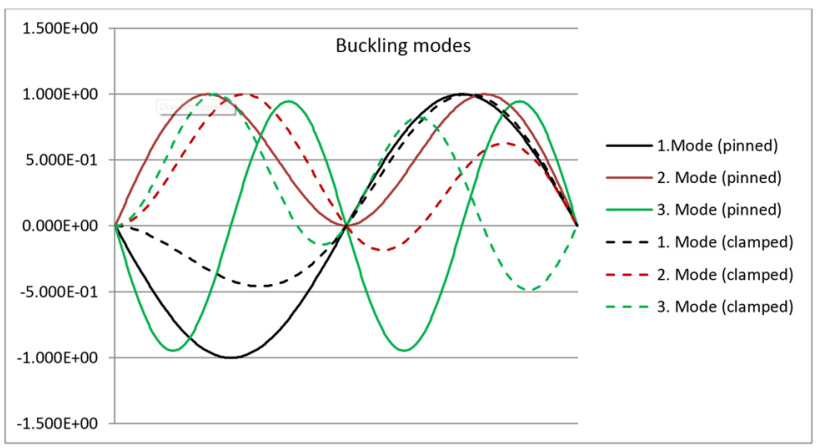

Fig. 10 Buckling modes for a two-span CLT-beam with different support conditions

(19), the shear modulus of the interface layer is computed by $G_{x z}^{(2)}=\frac{c_{s} \cdot h^{(2)}}{b^{(2)}}=\frac{50 \cdot 0.001}{0.05}=1.00 \mathrm{MPa}$. For the Young's modulus, we set $E_{x}^{(2)}=E_{x}^{(3)}$. For the static case, the single beam is loaded by a uniform transverse pressure $p_{z}=1.0$ $\mathrm{kN} / \mathrm{m}$. The boundary conditions are chosen for the simply 


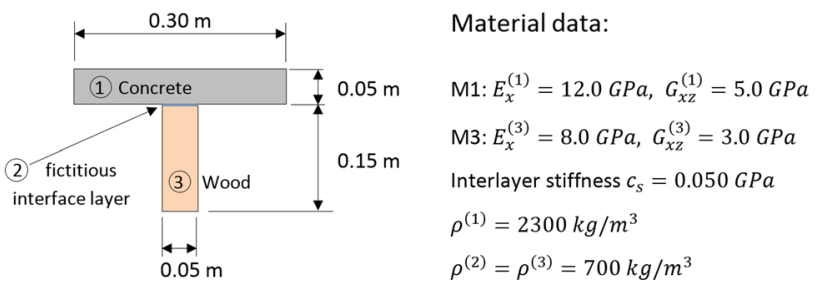

Fig. 11 Composite beam with two materials and partial interaction

supported case, at the left end $u_{0}(0)=w(0)=0$, at the right end $w(L)=0$.

Table 3 shows the excellent convergence of the anisoparametric finite elements (Wimmer and Gherlone 2017) and a comparison with existing solutions for a wide range of slenderness.
For the dynamic case, refer to $\mathrm{Xu}$ and $\mathrm{Wu}$ (2007b) who gave analytically exact solutions for a composite Timoshenko beam including the effect of shear deformation and rotary inertia. The comparison reflects three different boundary conditions (S...simply supported, C...clamped, F... free). In the clamped situations, all four degrees of freedom are set to zero. Table 4 shows very good agreement of RZT values with the solutions given in the above mentioned paper. It should be noticed, that the referenced solution is dependent on the choice of the shear correctors for which different approaches exist. The fourth example deals with a composite timber beam of non-rectangular cross section connected with discrete shear dowels (Kneidl and Hartmann 1995), see Fig. 12. The material data are given by $E_{x}^{(1)}=E_{x}^{(2)}=E_{x}^{(3)}=1.10 \cdot 10^{4} \mathrm{MPa}, G_{x z}^{(1)}=G_{x z}^{(3)}=6.90 \cdot 10^{2}$ $\mathrm{MPa}$. As in the example before, the problem is solved by
Table 3 Convergence study using anisoparametric $\mathrm{C}^{0}$ -finite elements for different slenderness ratios of a composite beam
Table 4 The first four natural frequencies in comparison to $\mathrm{Xu}$ and $\mathrm{Wu}(2007 \mathrm{~b})$

\begin{tabular}{|c|c|c|c|c|c|c|}
\hline $\mathrm{L} / \mathrm{h}$ & 4 Elem. & 10 Elem. & 20 Elem. & 40 Elem. & $\mathrm{Xu}$ and $\mathrm{Wu}(2007 \mathrm{~b})$ & $\begin{array}{l}\text { Girhammer } \\
\text { and Gopu } \\
\text { (1993) }\end{array}$ \\
\hline \multicolumn{7}{|c|}{ Maximum deflection at the center of span (mm) } \\
\hline 20 & 7.328 & 7.566 & 7.600 & 7.608 & 7.620 & 7.560 \\
\hline 10 & 0.7085 & 0.7283 & 0.7311 & 0.7318 & 0.7315 & 0.7172 \\
\hline 5 & 0.0670 & 0.0693 & 0.0696 & 0.0697 & 0.0700 & 0.0665 \\
\hline 4 & 0.0301 & 0.0311 & 0.0313 & 0.0313 & 0.0318 & 0.0296 \\
\hline \multicolumn{7}{|c|}{ Axial normal stress $\sigma_{x, o}$ at upper boundary at the center of span (MPa) } \\
\hline 20 & -2.244 & -2.229 & -2.228 & -2.228 & -2.225 & -2.218 \\
\hline 10 & -0.6894 & -0.6816 & -0.6809 & -0.6807 & -0.6780 & -0.6711 \\
\hline 5 & -0.2183 & 0.2166 & -0.2164 & -0.2164 & -0.2165 & -0.2102 \\
\hline 4 & -0.1474 & -0.1465 & -0.1464 & -0.1464 & -0.1479 & -0.1416 \\
\hline \multicolumn{7}{|c|}{ Axial normal stress $\sigma_{x, o}$ at lower boundary at the center of span (MPa) } \\
\hline 20 & 4.456 & 4.428 & 4.426 & 4.426 & 4.439 & 4.437 \\
\hline 10 & 1.354 & 1.339 & 1.338 & 1.338 & 1.344 & 1.342 \\
\hline 5 & 0.4243 & 0.4212 & 0.4209 & 0.4208 & 0.4202 & 0.4203 \\
\hline 4 & 0.2859 & 0.2843 & 0.2841 & 0.2841 & 0.2828 & 0.2832 \\
\hline \multicolumn{7}{|c|}{ Max. shear flow $\tau_{x z} \cdot b^{(3)}$ in fictitious interface layer at the support $(\mathrm{kN} / \mathrm{m})$} \\
\hline 20 & 11.91 & 11.51 & 11.44 & 11.42 & 11.43 & 11.44 \\
\hline 10 & 4.203 & 4.095 & 4.079 & 4.074 & 4.036 & 4.046 \\
\hline 5 & 0.9985 & 0.9865 & 0.9845 & 0.9840 & 0.9585 & 0.9630 \\
\hline 4 & 0.5745 & 0.5695 & 0.5685 & 0.5685 & 0.5511 & 0.5540 \\
\hline
\end{tabular}

\begin{tabular}{|c|c|c|c|c|c|c|}
\hline \multirow[t]{3}{*}{ Order } & \multicolumn{6}{|c|}{ Natural frequencies $(\mathrm{Hz})$} \\
\hline & \multicolumn{2}{|l|}{ SS } & \multicolumn{2}{|l|}{$\mathrm{CC}$} & \multicolumn{2}{|l|}{$\mathrm{CF}$} \\
\hline & $\begin{array}{l}\text { Xu and Wu } \\
(2007 b)\end{array}$ & RZT & $\begin{array}{l}X u \text { and } W u \\
(2007 b)\end{array}$ & RZT & $\begin{array}{l}\mathrm{Xu} \text { and Wu } \\
(2007 \mathrm{~b})\end{array}$ & RZT \\
\hline 1 & 10.30 & 10.27 & 18.70 & 18.33 & 3.994 & 3.930 \\
\hline 2 & 33.36 & 33.07 & 45.64 & 44.62 & 20.09 & 19.72 \\
\hline 3 & 65.88 & 64.93 & 83.21 & 81.36 & 48.75 & 47.74 \\
\hline 4 & 108.61 & 105.7 & 129.9 & 128.15 & 86.36 & 84.44 \\
\hline
\end{tabular}




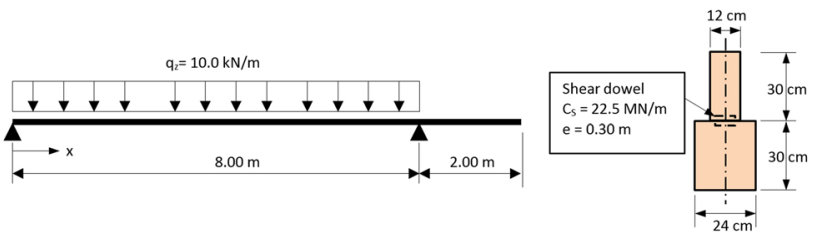

Fig. 12 Composite timber beam connected with discrete shear dowels

introducing a slip layer of $1 \mathrm{~mm}$ height. With the smeared interlayer stiffness $c_{s}=\frac{C_{s}}{e}=\frac{22.23}{0.30}=75 \mathrm{MN} / \mathrm{m}^{2}$ the fictitious shear modulus of this layer is determined by (Eq. 19) $G_{x z}^{(2)}=\frac{c_{s} \cdot h^{(2)}}{b^{(2)}}=\frac{75 \cdot 0.001}{0.12}=0.625 \mathrm{MPa}$.

Kneidl and Hartmann (1995) solved this problem by a two-part Bernoulli beam model, each part lying in the center-line of the partial cross section and connected by a truss ensemble which generates the shear flexibility of the connection. Figure 13 reports the distribution of the shear flow along the beam. In Fig. 14, representative cross sectional stress distributions are shown. The values in brackets and the dotted lines originate from the paper of Kneidl and Hartmann (1995). The stresses in the cantilever part form a self-equilibrating system, which is recorded very accurately.

\section{Conclusion}

This paper sets out an alternative, reliable and robust approach for the analysis of cross laminated timber elements under uniaxial bending in statics, stability and dynamics. The Refined Zigzag Theory, assessed as a competitive and accurate model for laminated composite structures is applied to CLT-beams. Comparisons with available beam solutions were made and show very good results. Hence, RZT-based finite elements, as implemented in the author's program ZZBEAM, can serve as an appropriate way to analyse the mechanical behaviour of CLT-structures. The layerwise distortion of the laminate's cross section is captured while the effort is independent of the number of layers. The method does not use any kind of shear correction factor and shows no locking behaviour. The RZT-kinematics is able to reflect the specific stress situation near concentrated loads in combination with a warping constraint as it can be usually detected only by 2D finite element calculations with high computational cost. The order of magnitude between

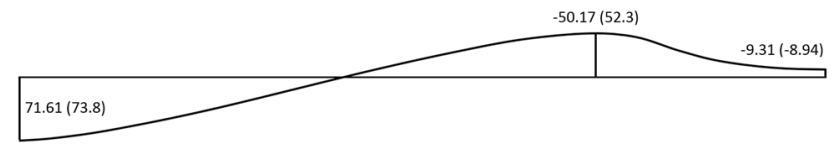

Fig. 13 Shear flow $(\mathrm{kN} / \mathrm{m})$ in the interface layer along the composite beam

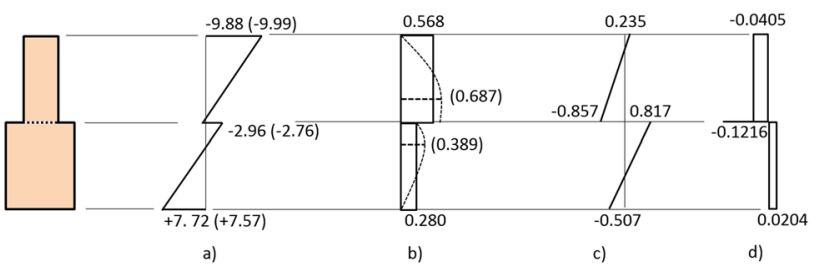

Fig. 14 Stress distributions in MPa: a axial bending stress at position $\mathrm{x}=4.00 \mathrm{~m}$, b shear stresses at left end, $\mathbf{c}$ axial stress and $\mathbf{d}$ mean shear stress at $x=9.00 \mathrm{~m}$

FSDT- and RZT-solutions concerning the maximum axial bending stress are presented for a two-span CLT-beam example. Stability investigations suggest that FSDT-based models are sufficiently accurate if the ratio of bending and shear stiffness is in a range as stated in the above example. By some modifications in the calculation of the zigzag function, non-rectangular cross sections can also be analyzed. Combined with the introduction of fictitious layers to simulate shear-compatible connectors, the method is applicable to a variety of composite wooden structural members, as demonstrated by a number of examples under static and dynamic loads.

Acknowledgements Karin Nachbagauer acknowledges support from the Austrian Science Fund (FWF): T733-N30. This contribution is an extended version of a conference paper presented at the CIVIL COMP 2019, Riva del Garda, Italy. The attendance of Heinz Wimmer at this conference has been supported by the Upper Austria University of Applied Sciences which is gratefully acknowledged.

Funding Open access funding provided by University of Applied Sciences Upper Austria.

Open Access This article is licensed under a Creative Commons Attribution 4.0 International License, which permits use, sharing, adaptation, distribution and reproduction in any medium or format, as long as you give appropriate credit to the original author(s) and the source, provide a link to the Creative Commons licence, and indicate if changes were made. The images or other third party material in this article are included in the article's Creative Commons licence, unless indicated otherwise in a credit line to the material. If material is not included in the article's Creative Commons licence and your intended use is not permitted by statutory regulation or exceeds the permitted use, you will need to obtain permission directly from the copyright holder. To view a copy of this licence, visit http://creativecommons.org/licenses/by/4.0/.

\section{References}

Abrate S, Di Sciuva M (2017) Equivalent single layer theories for composite and sandwich structures: a review. Compos Struct 179:482-494

Adam C, Heuer R, Jeschko A (1997) Flexural vibration of elastic composite beams with interlayer slip. Acta Mech 125:17-30 
Bogensperger T, Silly G, Schickhofer G (2012) Research Report “Comparison of methods of approximate verification procedures for cross laminated timber", published as bookchapter in Brandner et al. (2018)

Brandner R, Flatscher G, Ringhofer A, Schickhofer G, Thiel A (2016) Cross laminated timber (CLT): overview and development. Eur J Wood Prod 74:331-351

Brandner et al (eds) (2018) Properties, testing and design of cross laminated timber. A state-of-the-art report by COST Action FP1402/ WG 2, Shaker Verlag Aachen, ISBN 978-3-8440-6143-7

Carrera E (2003) Historical review of zig-zag theories for multi-layered plates and shells. Appl Mech Rev 56(3):287-308

EN 1995-1-1 (2015) Eurocode 5: design of timber structures-Part 1-1: general common rules for buildings, Annex B

Faella C, Martinelli E, Nigro E (2002) Steel and concrete composite beams with flexible shear connection: "exact" analytical expressions of the stiffness matrix and applications. Comput Struct 80:1001-1009

Flores FG, Oller S, Nallim L (2018) On the analysis of non-homogeneous laminates using the refined zigzag theory. Compos Struct 204:791-802

Gere JM (2001) Mechanics of materials, 5th edn. Brooks/Cole Pacific Grove, Pacific Grove

Gherlone M, Tessler A, Di Sciuva M (2011) C0 beam elements based on the refined zigzag theory for multi-layered composite and sandwich laminates. Compos Struct 93:2882-2894

Gherlone M (2013) On the use of zigzag functions in equivalent single layer theories for laminated composite and sandwich beams: a comparative study and some observations on external weak layers. J Appl Mech 80:061004-1-061004-19

Girhammar UA, Gopu D (1993) Composite beam-column with interlayer slip-exact analysis. J Struct Eng 119(4):1265-1282

Girhammar UA, Pan DH (1993) Dynamic analysis of composite members with interlayer slip. Int J Solids Struct 30(6):797-823

Girhammar UA, Pan DH (2007) Exact static analysis of partially composite beams and beam columns. Int J Mech Sci 49:239-255

Groh RMJ, Tessler A (2017) Computationally efficient beam elements for accurate stresses in sandwich laminates and laminated composites with delaminations. Comput Methods Appl Mech Eng 217:369-395

Guggenberger W, Moosbrugger T (2006) Mechanics of cross-laminated timber plates under uniaxial bending. In: 9 th world conference on timber engineering, Portland/Oregon

Huang S-J (2003) An analytical method for calculating the stress and strain in adhesive layers in sandwich beams. Compos Struct 60:105-114

Iurlaro L, Gherlone M, Di Sciuva M, Tessler A (2013) Assessment of the refined zigzag theory for bending, vibration, and buckling of sandwich plates: a comparative study of different theories. Compos Struct 106:777-792

Iurlaro L, Gherlone M, Di Sciuva M (2015) The (3,2)-Mixed Zigzag Theory for generally laminated beams: theoretical development and C0 finite elements formulation. Int J Solids Struct 73-74:1-19

Iurlaro L, Gherlone M, Mattone A, Di Sciuva M (2016) Experimental assessment of the Refined Zigzag Theory for the static bending analysis of sandwich beams. J Sandw Struct Mater 20(1):86-105

Kefal A, Hazim KA, Yildiz M (2018) A novel isogeometric beam element based on mixed form of refined zigzag theory for thick sandwich and multi-layered composite beams. Compos Part B Eng 167:100-121

Kneidl R, Hartmann H (1995) Träger mit nachgiebigem Verbund (Composite beams with partial interaction). Bauen mit $\mathrm{Holz}$ 4:285-290 (in German)

Kreuzinger H (1999) Flächentragwerke, Platten, Scheiben und Schalen, Berechnungsmethoden und Beispiele (Plates and shells, calculation methods and examples). In: Brücken aus Holz.
Informationsdienst Holz, Arbeitsgemeinschaft Holz e.V. Düsseldorf (in German)

Möhler K (1956) Über das Tragverhalten von Biegeträgern und Druckstäben mit zusammengesetzten Querschnitten und nachgiebigen Verbindungsmittels (On the load-bearing behaviour of beams and columns with composite cross-sections and flexible connections). Habilitation TH Karlsruhe (in German)

Nallim LG, Oller S, Oñate E, Flores FG (2017) A hierarchical finite element for composite laminated beams using a refined zigzag theory. Compos Struct 163:168-184

Nguyen Q, Martinelli E, Hjiaj M (2011) Derivation of the exact stiffness matrix for a two-layer Timoshenko beam element with partial interaction. Eng Struct 33:298-307

Nguyen Q, Hjiaj M (2012) Analytical approach for free vibration analysis of two-layer Timoshenko beams with interlayer slip. J Sound Vib 331:2949-2961

Oñate E, Eijo A, Oller S (2012) Simple and accurate two-noded beam element for composite laminated beams using a refined zigzag theory. Comput Methods Appl Mech Eng 213-216:362-382

Pagano NJ (1969) Exact solutions for composite laminates in cylindrical bending. J Compos Mater 3(3):398-411

Ranzi G, Bradford MA, Uy B (2004) A direct stiffness analysis of a composite beam with partial interaction. Int J Numer Methods Eng 61:657-672

Ranzi G, Bradford MA (2007) Direct stiffness analysis of a composite beam-column element with partial interaction. Comput Struct $85: 1206-1214$

Reddy JN (2004) Mechanics of laminated composite plates and shells. CRC Press, London

Salari MR, Spacone E (2001) Finite element formulations of onedimensional elements with bond-slip. Eng Struct 23:815-826

Schnabel S, Saje M, Turk G, Planinc I (2007) Analytical solutions of two-layer beam taking into account interlayer slip and shear deformation. J Struct Eng 133(6):886-894

Schnabel S, Planinc I (2011) The effect of transverse shear deformation on the buckling of two-layer composite columns with interlayer slip. Int J Non-Linear Mech 46:543-553

Scholz A (2002) Structural analysis of wooden plate structures. In: 4th international $\mathrm{PhD}$ symposium in civil engineering, Munich

Scholz A (2004) Ein Beitrag zur Berechnung von Flächentragwerken aus Holz (A contribution to the calculation of plate and shell structures made of wood). $\mathrm{PhD}$ thesis Technische Universität München (in German)

Tessler A, Di Sciuva M, Gherlone M (2009) A refined zigzag beam theory for composite and sandwich beams. J Compos Mater 43(9):1051-1081

Tessler A, Di Sciuva M, Gherlone M (2010) A consistent refinement of first-order shear deformation theory for laminated composite and sandwich plates using improved zigzag kinematics. J Mech Mater Struct 5(2):341-367

Tessler A (2015) Refined zigzag theory for homogeneous, laminated composite, and sandwich beams derived from Reissner's mixed variational principle. Meccanica 50:2621-2648

Thiel A (2013) ULS and SLS design of CLT and its implementation in the CLT designer. In: Focus solid timber solutions-European conference on cross laminates timber (CLT). University of Bath, pp 77-102

Wimmer H, Gherlone M (2017) Explicit matrices for a composite beam-column with refined zigzag kinematics. Acta Mech 228(6):2107-2117. https://doi.org/10.1007/s00707-017-1816-5

Wimmer H, Nachbagauer K (2018) Exact transfer- and stiffness matrix for the composite beam-column with Refined Zigzag kinematics. Compos Struct 189:700-706

Wimmer H, Nachbagauer K (2019) Multilayer composite beam-column with refined zigzag kinematics resting on variable two-parameter foundation. In: Zingoni A (ed) Advances in engineering materials, 
structures and systems: innovations, mechanics and applications. Taylor and Francis, London, pp 492-497

Xu R, Wu Y (2007a) Two-dimensional analytical solutions of simply supported beams with inter-layer slips. Int J Solids Struct 44:165-175

Xu R, Wu Y (2007b) Static, dynamic, and buckling analysis of partial interaction composite members using Timoshenko's beam theory. Int J Mech Sci 49:1139-1155
Publisher's Note Springer Nature remains neutral with regard to jurisdictional claims in published maps and institutional affiliations. 